\title{
Correlation between International Normalized Ratio values and sufficiency of two different local hemostatic measures in anticoagulated patients
}

\author{
Mohamed Zaghlool Amer ${ }^{1}$, Samah I. Mourad ${ }^{1}$, Ahmed S. Salem ${ }^{1,2}$, Ehab Abdelfadil ${ }^{1}$
}

Correspondence: Dr. Ehab Abdelfadil, Email: ehabident@yahoo.com

\begin{abstract}
'Department of Oral and Maxillofacial Surgery, Faculty of Dentistry, Mansoura University, Egypt, ${ }^{2}$ OMFS-IMPATH Research Group, Department of Imaging and Pathology, Faculty of Medicine, Catholic University Leuven, Belgium
\end{abstract}

\section{ABSTRACT}

Objectives:The management of patients receiving oral anticoagulant therapy (OAT) undergoing minor oral surgeries is controversial. This study was designed to evaluate the correlation between International Normalized Ratio (INR) values and the sufficiency of two different local hemostatic measures in controlling postextraction bleeding in anticoagulated patients. Materials and Methods: One hundred and sixty patients receiving Warfarin OAT were included in this study. Patients were selected so that 80 patients have INR values of $\leq 2$, whereas the remaining patients have the INR values ranging from 2 to 3 . Forty patients were then randomly selected from each category to form two equal groups. Forty-five patients who had never been on OAT were selected as a negative control group (group 1). Failure to achieve hemostasis using a pressure pack was managed using either tranexamic acid (group 2) or Ankaferd Blood Stopper (ABS) (group 3). Results: The INR values of patients included in group 2 and 3 ranged from 1.5 to 3, with a mean of 2.2. No significant difference was recorded between the use of either tranexamic acid or ABS in achieving hemostasis in anticoagulated patients with INR values ranging between 2 and $3(P=0.93)$. Conclusion: Based on our findings, ABS is a hemostatic agent of good efficacy. The effect of ABS in controlling post-extraction bleeding in anticoagulated patients with INR values $\leq 3$ is comparable to tranexamic acid with no evidence to support the superiority of tranexamic acid over ABS.

Key words: Gel foam, postextraction bleeding, tranexamic acid, warfarin, ankaferd

\section{INTRODUCTION}

The surgical management of anticoagulated patients has long been an issue of debate. Discontinuation of anticoagulated drugs when a minor oral surgery is to be undertaken has been a common practice. Multiple studies, however, reported this concept to be associated with high potential risks, and that minor surgeries can be performed safely in anticoagulated patients without interruption of the drug administration. ${ }^{[1-5]}$

Oral anticoagulant therapy (OAT) is prescribed for a variety of diseases. Such drugs suppress the activation of the hemostatic system resulting in increased bleeding tendency. ${ }^{[6-8]}$ Whether to stop, modify or continue the OAT when oral surgery is to be undertaken has long been a controversial issue. ${ }^{[9,10]}$ Warfarin is one of the most commonly used anticoagulated. It is a Vitamin K antagonist that results in a decreased effective protein C concentration. ${ }^{[11]}$

The most commonly used hemostatic measures include suturing, tranexamic acid, gel foam and cellulose. ${ }^{[12,13]}$ Despite the reported efficacy of such agents, the introduction of newer and more efficient agents is encouraged.

\footnotetext{
How to cite this article: Amer MZ, Mourad SI, Salem AS, Abdelfadil E. Correlation between International Normalized Ratio values and sufficiency of two different local hemostatic measures in anticoagulated patients. Eur J Dent 2014;8:475-80.

Copyright @ 2014 Dental Investigations Society. DOI: $10.4103 / 1305-7456.143628$
} 
The medicinal use of herbal extracts has been reported with promising results. ${ }^{[14,15]}$ Ankaferd Blood Stopper (ABS) is a drug of herbal origin that has an unclear mechanism of action. ${ }^{[16]}$ ABS has been reported to have different medicinal applications including hemostasis. ${ }^{[17,18]}$

This study was directed to evaluate the correlation between the International Normalized Ratio (INR) values and sufficiency of tranexamic acid and ABS in controlling postextraction bleeding in anticoagulated patients.

\section{MATERIALS AND METHODS}

This study was approved by the Review Board of the Faculty of Dentistry, Mansoura University and was conducted according to the World Medical Association Declaration of Helsinki on medical research protocols. All patients agreed and signed informed consent forms before being included in the study.

This study was conducted in the period from August 2011 to April 2013 and included 160 patients receiving Warfarin OAT for at least 1 year, as well as 45 patients who had never been on OAT. Patients were referred to Oral and Maxillofacial surgery Department, Faculty of Dentistry, Mansoura University for tooth extraction.

The values of the INR were measured for all patients preoperatively in the same day of tooth extraction using the standardized procedures. Forty-five patients who had never received OAT were selected and considered to be a negative control patients (group 1). One hundred and sixty patients receiving warfarin were representing a common pool for the anticoagulated patients included in this study. Eighty anticoaguated patients were restricted to INR value $<2$. The other 80 anticoagulated patients had their INR values ranging between 2 and 3 . Then, forty patients were randomly selected from each category of the anticoagulated patients by the second author (Mourad S) to form two equal groups using random numbers for assignment. Pre-extraction prophylactic antibiotic was prescribed when indicated. ${ }^{[19]}$ The medical conditions for which OAT is prescribed are shown in Table 1.

Only patients with a single tooth to be extracted that can be removed with forceps without the need for mucoperiosteal flap and/or dental elevators were included in this study. Patients with liver diseases, and those taking medications that would affect hemostasis such as non-steroidal anti-inflammatory drugs, heparin, and combined anti-platelet therapy were excluded. Additional exclusion criteria included previous thromboembolism under OAT and sever postextraction bleeding prior to starting OAT.

Before tooth extraction, a local anesthetic injection of $2 \%$ mepivacain hydrochlorid with 1:20,000 levonordefrin (Mepecain: Alexandria Co. for Pharmaceuticals, Alexandria, Egypt) was administered, and no more than two carpules were used for each patient. All extractions were performed by forceps as atraumatically as possible by the same surgeon (Salem A), who was unaware of the INR values. Following tooth extraction, all patients were instructed to apply pressure on the gauze pack for $15 \mathrm{~min}$.

Evidence of bleeding beyond the pressure pack was considered a postoperative bleeding. Such cases were managed initially by applying a gauze pressure pack with tranexamic acid for another 15 min for patients included within group 2, and by spraying ABS (Ankaferd Drug Inc, Istanbul, Turkey) over the extraction socket, followed by instructing the patients to bite on a gauze pressure pack for $15 \mathrm{~min}$ for patients included in group 3. Further failure of hemostasis was managed by application of gel foam in the extraction socket, which was then sutured with black silk suture (3-0) and the patient was instructed to bite on another gauze pack.

All patients were reexamined for postoperative bleeding $15 \mathrm{~min}$ after the procedures as well as on the $1^{\text {st }}, 2^{\text {nd }}$, and $5^{\text {th }}$ day after the extraction. Postoperatively; patients were given the routine post-extraction instructions, and paracetamol $500 \mathrm{mg}$ was prescribed as an analgesic.

All patients were instructed to report back to the operator immediately in case of any complaint of postoperative bleeding. The criteria described by Lockhart et al. ${ }^{[20]}$ was used to define whether the postoperative bleeding would be considered clinically

\begin{tabular}{lccc}
\multicolumn{4}{l}{ Table 1: Indications for OAT } \\
\hline Medical condition & Group 2 & Group 3 & Total \\
\hline Cardiac valve disease & 24 & 22 & 46 \\
Prosthetic valve & 12 & 16 & 28 \\
replacement & & & \\
Cerebrovascular accident & 8 & 8 & 16 \\
Atrial fibrillation & 12 & 10 & 22 \\
Pulmonary embolus & 8 & 6 & 14 \\
Ischemic heart disease & 16 & 18 & 34 \\
Total & 80 & 80 & 160 \\
\hline OAT: Oral anticoagulant therapy & & &
\end{tabular}


significant: Bleeding lasting for more than $12 \mathrm{~h}$, patient had return to the dental clinic or go to the emergency department, bleeding associated with large hematoma formation, and/or the necessity of blood transfusion.

Local hemostasis and postoperative bleeding were the criteria used to compare the groups included in this study. Data were processed using Microsoft Excel 2007 and Statistical Package for Social Science software (SPSS, Version 17.0; IBM SPSS Inc., Chicago, IL, USA). Student's $t$-test was used for analysis of the parametric while Kruskal-Wallis and Mann-Whitney U-tests were used for the non-parametric data. A significant difference was considered when $P<0.05$.

\section{RESULTS}

The age and gender distribution of patients included in this study is shown in Table 2. Group 1 (negative control group) included 22 females and 23 males, with the age ranging from 25 to 65 years (mean value of $39.9 \pm 12$ ). Group 2 (tranexamic acid group) included 36 females and 44 males, with the age ranging from 23 to 75 years (mean value of $59.9 \pm 10.1$ ). Group 3 (ABS group) included 38 females and 42 males, with the age ranging from 39 to 76 years (mean value of $57.4 \pm 9.3$ ). There was no significant difference concerning the gender between all groups $(P=0.906)$.

In group 1, teeth were extracted due to deep non-restorable caries in 29 patients and severe periodontitis in 16 patients, compared with 38 patients with deep caries and 42 with periodontitis in group 2. In group 3, 39 patients had deep non-restorable caries, and 41 had severe periodontitis.

For patients included in group 1, the INR values ranged from 0.9 to 1.2 with a mean of 1.1 , while, in the group 2, the INR levels ranged from 1.5 to 3 with a mean of 2.2. For group 3, it ranged from 1.6 to 3 , with a mean of 2.2. There was no significant difference between the INR levels between group 2 and group $3(P=0.794)$ [Table 3].

The incidence of postoperative bleeding is described in Table 4. No postoperative bleeding was encountered in group 1 (the negative control group), where biting on a gauze pack for 15 min was sufficient to control post-extraction bleeding. In contrast, 24 patients showed postoperative bleeding within group 2 , among whom ten patients showed a persistent bleeding after application of tranexamic acid. On the other hand, 21 patients showed postoperative bleeding in patients within group 3 , among whom eight patients showed a continuous bleeding after application of ABS. This was statistically significant compared to group 1 but not to group $2(P=0.000$ and 0.599$)$.

Twenty-four anticoagulated patients in group 2 showed continuous bleeding after application of the pressure pack (one patient of INR $\leq 2$ and 23 patients of INR $>2$ ). In an attempt to control bleeding, pressure pack with tranexamic acid was applied for another $15 \mathrm{~min}$. This maneuver successfully controlled the bleeding in fourteen patients. Ten patients of INR $>2$ required packing the extraction site with gel foam followed by figure of eight suturing and another pressure pack. In group 3, sole pressure packs failed to control bleeding in 21 patients (Two patients of INR $\leq 2$ and 19 patients of INR $>2$ ). Spraying Ankaferd successfully controlled bleeding in 13 patients. Eight patients of INR $>2$ required packing the extraction site with gel foam, followed by figure of eight suturing

\begin{tabular}{|c|c|c|c|}
\hline & Group 1 & Group 2 & Group 3 \\
\hline \multicolumn{4}{|l|}{ Age (year) } \\
\hline Range & $25-65$ & $23-75$ & $39-76$ \\
\hline Mean $\pm S D$ & $39.9 \pm 12$ & $55.9 \pm 10.1$ & $57.4 \pm 9.3$ \\
\hline \multicolumn{4}{|l|}{ Gender } \\
\hline Female & 22 & 36 & 38 \\
\hline Male & 23 & 44 & 42 \\
\hline
\end{tabular}

\begin{tabular}{|c|c|c|c|}
\hline & Group 1 & Group 2 & Group 3 \\
\hline \multicolumn{4}{|l|}{ INR } \\
\hline Range & $0.9-1.2$ & $1.5-3$ & $1.6-3$ \\
\hline Mean & 1.1 & 2.2 & 2.2 \\
\hline SD & 0.1 & 0.4 & 0.2 \\
\hline
\end{tabular}

\begin{tabular}{|c|c|c|c|c|}
\hline & Group 1 & Group 2 & Group 3 & Total \\
\hline \multicolumn{5}{|l|}{ POB } \\
\hline Yes & 0 & 24 & 21 & 45 \\
\hline No & 45 & 56 & 59 & 160 \\
\hline Total & 45 & 80 & 80 & 205 \\
\hline \multicolumn{5}{|c|}{ POB after secondary measures } \\
\hline Yes & N/A & 10 & 8 & 18 \\
\hline No & N/A & 14 & 13 & 27 \\
\hline
\end{tabular}


and another pressure pack [Table 4]. There was no significant difference between the secondary measures used to control postoperative bleeding (tranexamic acid/ABS) $(P=0.809)$.

Although, a remarkable increase in the incidence of postextraction bleeding among patients with INR values $>2$ was noted [Table 5], however, regarding to the sufficiency of simple pressure pack to control postextraction bleeding for patients with INR values of either $\leq 2$ or $>2$, no significant difference was recorded between groups 2 and $3(P=0.559$ and 0.374 respectively). On the other hand, when a secondary measure was used to control bleeding (tranexamic acid/ABS), no significant difference was recorded between groups 2 and $3(P=0.93)$, revealing no evidence to support the superiority of tranexamic acid over ABS.

None of the patients included in this study encountered bleeding after discharging from the institution. No infection was noted during the follow up, and healing was uneventful.

\section{DISCUSSION}

Postoperative bleeding is a complication that is frequently encountered in the dental office. Such bleeding is usually easily controlled in most cases. However, with increased bleeding tendency, the situation is usually more complicated. In such instances, the use of local hemostatic agents is usually indicated. ${ }^{[21,22]}$

Performing minor surgery was reported to be safe in patients with an INR of up to 2.5. ${ }^{[23]}$ Discontinuation of warfarin for 1-4 days preoperatively, causes the INR to fall below 1.5, which is very safe for any surgery to be undertaken. Following the surgery, warfarin can then be readministered. ${ }^{[24,25]}$ This protocol, however, does not guarantee the establishment of the 1.5 INR level. ${ }^{[24]}$

\begin{tabular}{|c|c|c|c|c|c|c|}
\hline \multirow{3}{*}{$\begin{array}{l}\text { INR } \\
\text { value }\end{array}$} & \multicolumn{6}{|c|}{ Postoperative bleeding } \\
\hline & \multicolumn{3}{|c|}{ Pressure pack } & \multicolumn{3}{|c|}{ Hemostatic agent } \\
\hline & Group 2 & Group 3 & $P$ & Group 2 & Group 3 & $P$ \\
\hline$\leq 2$ & 2 & 1 & 0.559 & 0 & 0 & $\mathrm{~N} / \mathrm{A}$ \\
\hline$>2$ & 19 & 23 & 0.374 & 8 & 10 & 0.93 \\
\hline Total & 21 & 24 & & 8 & 10 & \\
\hline
\end{tabular}

N/A: Not applicable, INR: International normalized ration
Our findings revealed that, a remarkable increase in the incidence of postextraction bleeding among patients of INR values $>2$. However, regarding the sufficiency of simple pressure pack to control postextraction bleeding for these patients with INR values of either $\leq 2$ or $>2$, no significant difference was recorded between $2^{\text {nd }}$ and $3^{\text {rd }}$ group $(P=0.559$ to 0.374$)$. These results can be attributed to equal division, separation and random inclusion of patients with INR values of either $\leq 2$ or $>2$, which lead to obtaining the same relative effect when simple pressure pack was used only in $2^{\text {nd }}$ and $3^{\text {rd }}$ group.

We found no evidence to support the superiority of tranexamic acid over ABS. In agreement with our results, several studies have reported tranexamic acid mouthwash to be an effective maneuver to control bleeding in anticoagulated patients undergoing oral surgical procedures, ${ }^{[2,4,26]}$ as well as fibrin glue, ${ }^{[27,28]}$ gelatin sponge and sutures. ${ }^{[22,29]}$ Recently, Blinder et al.,[22] compared three different hemostatic modalities (fibrin glue, tranexamic acid, gelatin sponge and sutures) and reported no significant differences concerning postoperative bleeding in anticoagulated patients following tooth extraction.

Furthermore, a clinically relevant bleeding was also reported in another study comparing patients with discontinuation of OAT versus those continuing with the anti-Vitamin $\mathrm{K}$ therapy. ${ }^{[10]}$ In fact, these bleeding events were more frequent in the control than in the test group (non-significant differences). In these cases, tranexamic acid mouthwashes $(4.8 \%, 10 \mathrm{ml}, 4$ times a day) were effective in controlling post-operative bleeding in all OAT patients without discontinuation.

Different factors can influence the postoperative bleeding following minor oral surgery in patients receiving OAT. Morimoto et al. ${ }^{[30]}$ reported a significantly increased postoperative bleeding associated with surgical extraction and acute inflammation. Other factors include the operator's experience and the surgical technique. In our study, all extractions were done by one qualified oral surgeon with more than 10 years of experience (Salem A). All teeth extractions were done as atraumatic as possible by simple forceps extraction technique.

A wide range of the incidence of postoperative bleeding following dental extraction in anticoagulated patients has been reported in the literature. ${ }^{[22,24,31,32]}$ Perhaps the different modalities used to control the bleeding initially in such patients can explain this 
diversity. Packing of the extraction socket with a local hemostatic agent combined with suturing appears to be associated with decreased bleeding incidence. ${ }^{[24,31]}$ In our study, the incidence of postoperative bleeding following the use of local hemostatic agents was $12.5 \%$ and $10 \%$ in group 2 (tranexamic acid) and group 3 (ABS) respectively. These results were in accordance with Blinder et al. ${ }^{[22]}$ who reported an incidence of $12 \%$ in his study.

The incidence of postoperative bleeding in our results is considered high in relation to others. This may be attributed to different factors. Suturing of extraction socket, for instances; results in apposition of the socket margins and helps in controlling the bleeding. In our technique, we used only a pressure pack for $15 \mathrm{~min}$, then another pack saturated with the hemostatic agent to test the ability of the material to control bleeding without the additional effect of sutures.

Another reason could be the presence of inflammation in a considerable number of the extracted teeth. When dealing with severe periodontitis and periapical infection, sometimes tooth removal is essential for resolution of inflammation. Teeth included in this study were removed due to sever periodontits (51.9\%), and deep caries with/without chronic periapical infection $(48.1 \%)$. The predominant granulation tissue associated with chronic infection, combined with other inflammatory signs can contribute to the increased incidence of postoperative bleeding.

Ankaferd Blood Stopper is unique hemostatic agent of herbal origin that was used for those patients who did not respond to plain pressure pack with the need of additional application of local hemostatic agent. Although, the ABS mechanism of action still unclear, Goker et al. ${ }^{[16]}$ described rapid formation of a protein network in response to exposure to ABS. This network enhances RBCs aggregation. The network formation is reported to be related to the functions of blood proteins and red blood cells.

Ankaferd Blood Stopper is reported to induce physiological hemostatic process with no effect on individual clotting factors. This mechanism combined with providing tissue oxygenation renders ABS superior to other hemostatic agents of gerbil origin. ${ }^{[33,34]}$ Moreover, In an in vivo study on rats, Cipil et al. .35] $^{\text {[3. }}$ reported a marked shortening of bleeding following leg amputation in response to topical application of ABS.
Tranexamic acid is perhaps the most commonly used local hemostatic agent. It combines the ease of application with low cost, and it is an effective hemostatic agent. Agents of herbal origin, on the other hand, usually have a wider scope of activity. Besides being a good hemostatic agent, ABS has many other positive actions. It is reported to have antimicrobial activity, ${ }^{[36]}$ and to decrease inflammation and necrosis of bone and at the same time enhance new bone formation in early bone healing period, ${ }^{[17]}$ which are all desired properties following tooth extractions.

To the best of our knowledge, and according to our results we believe that although, AOT patients represent a troublesome condition confronting oral surgeon during early postextraction phase regarding to the variable expected bleeding risk. However, simple pressure pack for a proper time of application can play a pivotal role to control such risk for AOT patients with INR values $\leq 2$. On the other hand, for those patients with INR values $>2$ ABS can represent itself as a sufficient local hemostatic agent that is comparable with tranexamic acid.

\section{CONCLUSION}

Based on our findings, ABS is an effective hemostatic agent comparable to tranexamic acid in controlling post-extraction bleeding in AOT patients of INR values $\leq 3$ with no evidence support the superiority of tranexamic acid over ABS.

\section{REFERENCES}

1. Wahl MJ. Dental surgery in anticoagulated patients. Arch Intern Med 1998;158:1610-6.

2. Ramström G, Sindet-Pedersen S, Hall G, Blombäck M, Alander U. Prevention of postsurgical bleeding in oral surgery using tranexamic acid without dose modification of oral anticoagulants. J Oral Maxillofac Surg 1993;51:1211-6.

3. Souto JC, Oliver A, Zuazu-Jausoro I, Vives A, Fontcuberta J. Oral surgery in anticoagulated patients without reducing the dose of oral anticoagulant: A prospective randomized study. J Oral Maxillofac Surg 1996;54:27-32.

4. Sindet-Pedersen S, Ramström G, Bernvil S, Blombäck M. Hemostatic effect of tranexamic acid mouthwash in anticoagulant-treated patients undergoing oral surgery. N Engl J Med 1989;320:840-3.

5. Zusman SP, Lustig JP, Baston I. Postextraction hemostasis in patients on anticoagulant therapy: The use of a fibrin sealant. Quintessence Int 1992;23:713-6.

6. Brimble KS, Ingram AJ, Eikelboom JW, Hart RG. Anticoagulants in patients with atrial fibrillation and end-stage renal disease. Postgrad Med 2012;124:17-25.

7. Jacomella V, Corti N, Husmann M. Novel anticoagulants in the therapy of peripheral arterial and coronary artery disease. Curr Opin Pharmacol 2013;13:294-300.

8. Conway EM, Bauer KA, Barzegar S, Rosenberg RD. Suppression of hemostatic system activation by oral anticoagulants in the blood of patients with thrombotic diatheses. J Clin Invest 1987;80:1535-44. 
9. Ferrieri GB, Castiglioni S, Carmagnola D, Cargnel M, Strohmenger L, Abati S. Oral surgery in patients on anticoagulant treatment without therapy interruption. J Oral Maxillofac Surg 2007;65:1149-54.

10. Sacco R, Sacco M, Carpenedo M, Mannucci PM. Oral surgery in patients on oral anticoagulant therapy: A randomized comparison of different intensity targets. Oral Surg Oral Med Oral Pathol Oral Radiol Endod 2007;104:e18-21.

11. Walker CP, Royston D. Thrombin generation and its inhibition: A review of the scientific basis and mechanism of action of anticoagulant therapies. Br J Anaesth 2002;88:848-63.

12. Petersen JK, Krogsgaard J, Nielsen KM, Nørgaard EB. A comparison between 2 absorbable hemostatic agents: Gelatin sponge (Spongostan) and oxidized regenerated cellulose (Surgicel). Int J Oral Surg 1984;13:406-10.

13. Bacci C, Maglione M, Favero L, Perini A, Di Lenarda R, Berengo M, et al. Management of dental extraction in patients undergoing anticoagulant treatment. Results from a large, multicentre, prospective, case-control study. Thromb Haemost 2010;104:972-5.

14. Thosar N, Basak S, Bahadure RN, Rajurkar M. Antimicrobial efficacy of five essential oils against oral pathogens: An in vitro study. Eur J Dent 2013;7:S71-7.

15. Mistry KS, Sanghvi Z, Parmar G, Shah S. The antimicrobial activity of Azadirachta indica, Mimusops elengi, Tinospora cardifolia, Ocimum sanctum and $2 \%$ chlorhexidine gluconate on common endodontic pathogens: An in vitro study. Eur J Dent 2014;8:172-7.

16. Goker H, Haznedaroglu IC, Ercetin S, Kirazli S, Akman U, Ozturk Y, et al. Haemostatic actions of the folkloric medicinal plant extract Ankaferd Blood Stopper. J Int Med Res 2008;36:163-70.

17. Isler SC, Demircan S, Cakarer S, Cebi Z, Keskin C, Soluk M, et al. Effects of folk medicinal plant extract Ankaferd Blood Stopper on early bone healing. J Appl Oral Sci 2010;18:409-14.

18. Yaman E, Görken F, Pinar Erdem A, Sepet E, Aytepe Z. Effects of folk medicinal plant extract Ankaferd Blood Stopper( $\left({ }^{\circledR}\right)$ in vital primary molar pulpotomy. Eur Arch Paediatr Dent 2012;13:197-202.

19. Wilson W, Taubert KA, Gewitz M, Lockhart PB, Baddour LM, Levison M, et al. Prevention of infective endocarditis: Guidelines from the American Heart Association: A guideline from the American Heart Association Rheumatic Fever, Endocarditis and Kawasaki Disease Committee, Council on Cardiovascular Disease in the Young, and the Council on Clinical Cardiology, Council on Cardiovascular Surgery and Anesthesia, and the Quality of Care and Outcomes Research Interdisciplinary Working Group. J Am Dent Assoc 2008;139 Suppl: 3S-24.

20. Lockhart PB, Gibson J, Pond SH, Leitch J. Dental management considerations for the patient with an acquired coagulopathy. Part 1: Coagulopathies from systemic disease. Br Dent J 2003;195:439-45.

21. Venkateshwar GP, Padhye MN, Khosla AR, Kakkar ST. Complications of exodontia: A retrospective study. Indian J Dent Res 2011;22:633-8.

22. Blinder D, Manor Y, Martinowitz U, Taicher S, Hashomer T. Dental extractions in patients maintained on continued oral anticoagulant: Comparison of local hemostatic modalities. Oral Surg Oral Med Oral Pathol Oral Radiol Endod 1999;88:137-40.

23. Guidelines on oral anticoagulation: Third edition. Br J Haematol 1998;101:374-87.
24. Devani P, Lavery KM, Howell CJ. Dental extractions in patients on warfarin: Is alteration of anticoagulant regime necessary? Br J Oral Maxillofac Surg 1998;36:107-11.

25. Mulligan R, Weitzel KG. Pretreatment management of the patient receiving anticoagulant drugs. J Am Dent Assoc 1988;117:479-83.

26. Bernardoni-Socorro C, Arteaga-Vizcaino M, Villamizar Y, Diez-Ewald M, Vizcaíno-Salazar G, Torres-Guerra E, et al. Mouth-washing with tranexamic acid in patients treated with oral anticoagulants subjected to oral surgery procedures. Invest Clin 1998;39:77-83.

27. Bodner L, Weinstein JM, Baumgarten AK. Efficacy of fibrin sealant in patients on various levels of oral anticoagulant undergoing oral surgery. Oral Surg Oral Med Oral Pathol Oral Radiol Endod 1998;86:421-4.

28. Rakocz M, Mazar A, Varon D, Spierer S, Blinder D, Martinowitz U. Dental extractions in patients with bleeding disorders. The use of fibrin glue. Oral Surg Oral Med Oral Pathol 1993;75:280-2.

29. Blinder D, Martinowitz U, Ardekian L, Peleg M, Taicher S. Oral surgical procedures during anticoagulant therapy. Harefuah 1996;130:681-3, 727.

30. Morimoto Y, Niwa H, Minematsu K. Risk factors affecting postoperative hemorrhage after tooth extraction in patients receiving oral antithrombotic therapy. J Oral Maxillofac Surg 2011;69:1550-6.

31. Zanon E, Martinelli F, Bacci C, Cordioli G, Girolami A. Safety of dental extraction among consecutive patients on oral anticoagulant treatment managed using a specific dental management protocol. Blood Coagul Fibrinolysis 2003;14:27-30.

32. Salam S, Yusuf H, Milosevic A. Bleeding after dental extractions in patients taking warfarin. Br J Oral Maxillofac Surg 2007;45:463-6.

33. Adachihara A. Oral treatment of hemophilia A using traditional kanpo medicine, Huang-lien-chieh-tu-tang (plant extract). Haemostasis 1983;13:78-82.

34. Gao J, Hooker BS, Anderson DB. Expression of functional human coagulation factor XIII A-domain in plant cell suspensions and whole plants. Protein Expr Purif 2004;37:89-96.

35. Cipil HS, Kosar A, Kaya A, Uz B, Haznedaroglu IC, Goker H, et al. In vivo hemostatic effect of the medicinal plant extract Ankaferd Blood Stopper in rats pretreated with warfarin. Clin Appl Thromb Hemost 2009;15:270-6.

36. Tasdelen Fisgin N, Tanriverdi Cayci Y, Coban AY, Ozatli D, Tanyel E, Durupinar B, et al. Antimicrobial activity of plant extract Ankaferd Blood Stopper. Fitoterapia 2009;80:48-50.

\begin{tabular}{|c|c|}
\hline \multicolumn{2}{|c|}{ Access this article online } \\
\hline Quick Response Code: & $\begin{array}{l}\text { Website: } \\
\text { www.eurjdent.com }\end{array}$ \\
\hline 19yctids & $\begin{array}{l}\text { Source of Support: Nill. } \\
\text { Conflict of Interest: None declared }\end{array}$ \\
\hline
\end{tabular}

